infrequently performed in the United Kingdom. We however, have persisted with video assisted thoracoscopic (VATS) LVRS and report the results of our first 200 operations.

Patients/methods Surgical candidates for LVRS were selected by a multidisciplinary team approach using radionuclide scintigraphy in all cases. After the initial 20 open cases we adopted policy of two stage bilateral VATS LVRS with the timing of the second operation determined by the patient. 160 patients have completed one-stage LVRS: median age 60 (39-73) years and 20 patients have completed two-stage bilateral LVRS: median age 59 (41-66) years. Data from a prospective database were analysed to assess the postoperative changes in pulmonary function and health status (SF 36 questionnaire) recorded at three, six and, twelve months and thence annually.

Results 30 -day mortality was $6 \%$ and $25 \%$ required post-operative ventilation ( 9 of 50 for $<24$ h). Hospital stay was 14 (2-110) days. $\mathrm{FEV}_{1}$ in both groups showed significant continuous improved at the 3-month, 6-month and 1-year postoperative review ( $p \leq 0.035$ ). Furthermore, significant improvements $(p \leq 0.05)$ in SF 36 were seen across the seven domains assessed: Physical Functioning (up to 1 year), Social Functioning (up to 1 year), Role-Physical (up to 1 year), Role-Emotional (at 5 years), Mental Health (up to 1 year), Energy/Vitality (up to 1 year), and General Health (up to 1 year). There has however been a significant reduction in the domain of Bodily Pain up to 4 years post LVRS $(p \leq 0.05)$. More lasting improvements are seen in two-stage bilateral group compared to the one-stage group.

Conclusion The use of a multidisciplinary team approach and a prolonged surgical strategy can achieve durable postoperative benefits from LVRS for up to 4 years with acceptable risk.

\section{P142 INFLAMMATORY CELLS IN THE QUADRICEPS OF COPD PATIENTS AND RESPONSE TO RESISTANCE TRAINING}

doi:10.1136/thx.2010.150987.43

M K Menon, L Houchen, S Harrison, S J Singh, M D L Morgan, P Bradding, M C Steiner. Pulmonary Rehabilitation Research Group, Glenfield Hospital, Leicester, UK

Background Physical exercise in healthy individuals leads to an acute inflammatory-cell response in skeletal muscles. In COPD, quadriceps dysfunction is an important systemic manifestation that can be offset by exercise training. However, the nature of the muscle inflammatory response in these patients to acute and chronic exercise remains unknown. We therefore measured inflammatory cell infiltration in the quadriceps of COPD patients and healthy controls, in response to a programme of lower-limb resistance training.

Methods 12 COPD patients (mean (SD) age 66.7(7.0) years, BMI $26.1(7.2) \mathrm{kg} / \mathrm{m}^{2}, \mathrm{FEV}_{1} 46.4$ (20.5) \% predicted, 10 males) and seven healthy controls (66.7 (5.1) years, BMI $27.7(2.4) \mathrm{kg} / \mathrm{m}^{2}, \mathrm{FEV}_{1} 103.4$ $(17.0) \%$ predicted, five males) underwent 8 weeks of bilateral lowerlimb, high-intensity resistance training, thrice weekly, on an isokinetic dynamometer (Cybex II Norm). Quadriceps muscle biopsies from the dominant thigh were obtained at baseline (T0), 24-h after the 1st exercise bout (T1), and 24-h after the last exercise session following 8-weeks training (T2). Glycol methacrylate-embedded muscle biopsies were analysed using immunohistochemistry. Inflammatory cells were identified using antibodies against neutrophil elastase (NE) and CD163 (macrophages). Dual energy x-ray Absorptiometry (DEXA) was used to determine thigh muscle mass and isometric quadriceps strength was measured on the cybex.
Results At T0, neutrophils were not detected in any of the healthy controls, but were present in six out of 12 patients. A significant increase in neutrophil and macrophage counts in both patients and controls was seen at T1 (Abstract P142 Table 1). At T2, inflammatory cell counts in both groups were close to baseline values. Isometric quadriceps strength (COPD: pre vs post -134.0 (44.0) vs 151.8 (47.9) Nm, $p=0.002$; Healthy: pre vs post 153.4 (42.4) vs 169.0 (43.1) $\mathrm{Nm}, \mathrm{p}=0.04]$ and thigh lean mass (COPD: pre vs post 4.4 (1.2) vs 4.7 (1.2) kg, p=0.003; Healthy: pre vs post 4.5 (0.6) vs 4.7 $(0.7) \mathrm{kg}, \mathrm{p}=0.004$ ] increased significantly after training in both groups.

Conclusions Acute resistance exercise in COPD leads to an inflammatory-cell response in the quadriceps that is comparable to healthy controls. Regular training results in muscle adaptation characterised by a diminished inflammatory response to a bout of exercise.

\section{Abstract P142 Table 1}

\begin{tabular}{|c|c|c|c|}
\hline & TO & T1 & T2 \\
\hline \multicolumn{4}{|c|}{$\mathrm{NE}$ (cells $/ \mathrm{mm}^{2}$ interstitial area) } \\
\hline $\operatorname{COPD}(n=12)$ & $4.1(0.0-21.0)$ & $137.9(30.1-217.9)^{*}$ & $0.0(0.0-15.9) \neq$ \\
\hline Healthy $(n=7)$ & $0.0(0.0-0.0)$ & $153.4(13.0-305.5) \dagger$ & $14.2(0.0-17.3)$ \\
\hline \multicolumn{4}{|c|}{ CD163 (cells $/ \mathrm{mm}^{2}$ interstitial area) } \\
\hline $\operatorname{COPD}(n=12)$ & $10.4(2.1-34.1)$ & $90.3(40.9-135.7) \dagger$ & $26.9(12.7-72.5)$ \\
\hline Healthy $(n=7)$ & $0.0(0.0-27.0)$ & $146.7(64.3-172.2) \dagger$ & $0.0(0.0-59.2) \S$ \\
\hline \multicolumn{4}{|c|}{ Data at various time-points compared using nonparametric repeated measures ANOVA } \\
\hline
\end{tabular}

\section{P143 NF-KAPPA B (NF-KB) AND ACTIVATOR PROTEIN-1 (AP-1) DNA BINDING IN THE QUADRICEPS OF COPD PATIENTS}

doi:10.1136/thx.2010.150987.44

${ }^{1} \mathrm{~S}$ A Natanek, ${ }^{2} \mathrm{R}$ C J Langen, ${ }^{2} \mathrm{H}$ R Gosker, ${ }^{1} \mathrm{G}$ S Marsh, ${ }^{2} \mathrm{~S}$ Slot, ${ }^{1} \mathrm{~N}$ S Hopkinson, ${ }^{1} \mathrm{~W}$ D-C Man, ${ }^{3} \mathrm{P}$ R Kemp, ${ }^{4} \mathrm{~J}$ Moxham, ${ }^{2} \mathrm{~A}$ M W J Schols, ${ }^{1} \mathrm{M}$ I Polkey. ${ }^{1} \mathrm{NIHR}$ Respiratory Biomedical Research Unit of the Royal Brompton and Harefield NHS Foundation Trust and National Heart \& Lung Institute, Imperial College London, London, UK; ${ }^{2}$ NUTRIM School for Nutrition, Toxicology \& Metabolism, Maastricht University, Maastricht, the Netherlands; ${ }^{3}$ National Heart \& Lung Institute, Imperial College London, London, UK; ${ }^{4}$ Guy's, King's and St Thomas' School of Medicine, London, UK

Introduction Animal work implicates NF- $\mathrm{KB}$ and AP-1 activation in muscle atrophy (Cai et al, 2004 and Costelli et al, 2005). Prior study of seven COPD patients with a low BMI and seven COPD patients with a normal BMI suggested that NF- $\kappa B$ DNA binding was increased in the former (Agusti et al, 2004) although others have not demonstrated NF- $\kappa B$ activation in COPD muscle (Plant et al, 2009). Aim Evaluate NF- $\kappa$ B and AP-1 activation in the quadriceps of patients with stable COPD in relation to muscle atrophy.

Methods 114 COPD patients and 30 healthy age-matched controls underwent measurements of lung function and bioelectrical impedance to determine fat-free mass index (FFMI) and a percutaneous Bergstrom needle biopsy of the quadriceps. Transcription factor ELISAs were performed on nuclear extracts from quadriceps muscle to measure quantities of NF-kB P50, P65, and AP-1 c-jun subunits in muscle nuclei capable of binding DNA. Immunohistochemistry was used to determine type I and II fibre cross-sectional area (CSA) from muscle sections. 
Results There was no evidence of increased quantities of muscle nuclear P65 or P50 binding DNA in patients compared with controls and the quantity of muscle nuclear AP-1 c-jun binding DNA was lower in patients than controls $(336(174,513)$ RLU vs $508(284,846)$ RLU, $p=0.01$ ). Patients with low FFMI ( $\leq 15$ and $16 \mathrm{~kg} / \mathrm{m}^{2}$ for females and males respectively, $\mathrm{n}=54$ ) did not have increased quantities of P65, P50 or c-jun binding DNA compared with patients with normal FFMI ( $\mathrm{n}=60$, (286 (171,407) vs $260(176,376)$ RLU $\mathrm{p}=0.94,880(400,1373)$ vs $1064(654,1586)$ RLU $p=0.33$ and 313 $(155,484)$ vs $353(181,570)$ RLU $p=0.42$ respectively). There were no correlations between quantities of the transcription factors binding DNA and quadriceps type I or II fibre CSA or type I, IIa or IIx fibre proportions.

Conclusion NF- $\kappa \mathrm{B}$ and AP-1 DNA-binding were not increased in the quadriceps of patients with stable COPD compared to controls and did not predict reduced FFMI or quadriceps fibre size, nor quadriceps fibre proportions, in patients.

\section{P144 MUSCLE FIBRE ATROPHY AND AEROBIC TO ANAEROBIC FIBRE TYPE SHIFT IN THE QUADRICEPS IN COPD}

doi:10.1136/thx.2010.150987.45

${ }^{1} \mathrm{~S}$ A Natanek, ${ }^{1} \mathrm{H}$ R Gosker, ${ }^{2} \mathrm{~S}$ Slot, ${ }^{1} \mathrm{G}$ S Marsh, ${ }^{2} \mathrm{R}$ C J Langen, ${ }^{1} \mathrm{~N}$ S Hopkinson, ${ }^{1}$ W D-C Man, ${ }^{3} \mathrm{~J}$ Moxham, ${ }^{4} \mathrm{P}$ R Kemp, ${ }^{2} \mathrm{~A}$ M W J Schols, ${ }^{1} \mathrm{M}$ I Polkey. ${ }^{1} \mathrm{~N} I H R$ Respiratory Biomedical Research Unit of the Royal Brompton and Harefield NHS Foundation Trust and National Heart \& Lung Institute, Imperial College London, London, UK; ${ }^{2}$ NUTRIM School for Nutrition, Toxicology \& Metabolism, Maastricht University, Maastricht, the Netherlands; ' ${ }^{G}$ uy's, King's and Thomas' School of Medicine, London, UK; ${ }^{4}$ Molecular Medicine Section, National Heart \& Lung Institute, Imperial College London, London, UK

Introduction Quadriceps dysfunction is associated with reduced exercise tolerance and survival in COPD. Quadriceps dysfunction has been attributed to quadriceps fibre atrophy (FA) and oxidative to glycolytic (type I to II) fibre shift (FS) but the prevalence of FA and FS and their individual relationships with exercise capacity are not clear.

Methods We measured lung function, physical activity, fat-free mass index (FFMI), quadriceps strength and endurance and exercise performance (6-min walk and incremental cycle ergometry) in 114 COPD patients and 30 healthy age-matched controls and measured mid-thigh muscle cross-sectional area (MTCSA) by CT in 30 patients and 10 controls. Each subject had a quadriceps biopsy and type I, IIa and IIx fibre proportions and CSA were determined by immunohistochemistry. FA and FS were defined using reference intervals for quadriceps fibre characteristics derived from the controls.

Results $24 \%$ of patients had quadriceps fibre characteristics within normal limits, 31\% had isolated FS, 20\% had isolated FA (predominantly type II FA) and 25\% had both FS and FA. Muscle FA could not be discerned by FFMI, MT $\mathrm{CSA}_{\mathrm{A}}$ or quadriceps strength values. Patients with isolated FS had a poorer exercise performance than patients with normal fibres $(6 \mathrm{MW} \%$ predicted $66(46,82)$ vs 77 $(63,95), \mathrm{p}=0.025$ and peak $\mathrm{VO}_{2} \%$ predicted $41(28,48)$ vs $50(38,58)$, $\mathrm{p}=0.008)$, patients with isolated FA $(6 \mathrm{MW} \%$ predicted $66(46,82)$ vs $91(70,103), \mathrm{p}=0.001$ and peak $\mathrm{VO}_{2} \%$ predicted $41(28,48) \mathrm{v} 49$ $(39,62), p=0.006)$ and patients with both FS and FA (6MW \% predicted $66(46,82)$ vs $79(63,89), p=0.01)$. Patients with isolated FA or both FS and FA did not have a reduced exercise performance vs patients with normal muscle $(6 \mathrm{MW} \%$ predicted $\mathrm{p}=0.14$ and 0.53 and peak $\mathrm{VO}_{2} \%$ predicted $\mathrm{p}=0.98$ and $\mathrm{FA}$ vs normal and FS plus FA vs normal respectively). Stepwise multiple regression confirmed that type I fibre proportion was a positive predictor and type IIa fibre CSA was a negative predictor of $6 \mathrm{MW}$ and cycle performance in patients, independent of lung function impairment.

Conclusion Quadriceps FA and FS do not necessarily co-occur in COPD. FS is associated with impaired exercise tolerance whereas FA is associated with preserved exercise capacity in COPD.

\section{P145 EVALUATION OF A QUADRICEPS MUSCLE ENDURANCE LEG LIFT TEST IN PATIENTS WITH CHRONIC OBSTRUCTIVE PULMONARY DISEASE}

doi:10.1136/thx.2010.150987.46

${ }^{1} \mathrm{~S}$ Hattle, ${ }^{1} \mathrm{C}$ Hayton, ${ }^{1} \mathrm{~J}$ Elia, ${ }^{2} \mathrm{~A} \mathrm{M}$ Wilson. ${ }^{1}$ Norfolk and Norwich University Hospital, Norwich, UK; ${ }^{2}$ University of East Anglia, Norwich, UK

Introduction and objectives Quadriceps muscle strength is commonly used to assess patients with chronic obstructive pulmonary disease (COPD). However a simple endurance test is not routinely available. We wished to evaluate a simple test of muscle endurance.

Methods We developed a quadriceps muscle leg lift test whereby seated patients extended their dominant leg from $90^{\circ}$ flexion to $0^{\circ}$ flexion for $5 \mathrm{~s}$ with a weight ( $2 \mathrm{~kg}$ for Men and $1 \mathrm{~kg}$ for women) strapped to their ankle. They repeated cycles of flexion and extension (with $5 \mathrm{~s}$ hold at each extension) until exhaustion. The duration of this test and number of lifts was compared to the duration and distance walked during an endurance shuttle walk test (at the speed equivalent to $85 \%$ of maximum oxygen uptake as determined from an incremental shuttle walk test), muscle strength (using an dynometer) and the dyspnoea and fatigue domains of the Chronic Respiratory Questionnaire (CRQ).

Results 43 (30 Males) patients with COPD with mean (standard deviation) of 68.9 (9.3) years and forced expiratory volume in $1 \mathrm{~s}$ $\left(\mathrm{FEV}_{1}\right)$ of 42.5 (13.8) percent of predicted normal completed the tests. The mean (standard deviation) quadriceps strength was 16.1 (5.0) $\mathrm{kg}$, number of lifts was 12.5 (7.1) in 85.2 (48.3) s, endurance shuttle-walk test (ESWT) distance was 177.3 (89.8) $\mathrm{m}$ in 184.7 (88.8) s and dyspnoea and fatigue domains of the CRQ were 2.4 (1.1) and 3.3 (1.2) respectively. The correlation coefficients comparing the measures are shown in Abstract P145 Table 1.

Conclusion The endurance leg lift test was closely associated with the fatigue domain of the Chronic Respiratory Questionnaire but poorly associated with the dyspnoea domain. This new test may have some clinical utility given that it more closely relates to fatigue than either muscle strength or the endurance shuttle-walk test.

\section{Abstract P145 Table 1}

\begin{tabular}{llclll}
\hline & $\begin{array}{l}\text { Quadriceps } \\
\text { strength }\end{array}$ & $\begin{array}{l}\text { Leg lifts } \\
\text { number }\end{array}$ & $\begin{array}{l}\text { Leg lifts } \\
\text { duration }\end{array}$ & $\begin{array}{l}\text { ESWT } \\
\text { distance }\end{array}$ & ESWT- duration \\
\hline Quadriceps strength & 1.000 & 0.219 & 0.129 & 0.067 & 0.062 \\
Leg lifts-number & 0.219 & 1.000 & 0.967 & 0.165 & 0.100 \\
Leg lifts-duration & 0.129 & 0.967 & 1.000 & 0.226 & 0.194 \\
ESWT-distance & 0.067 & 0.165 & 0.226 & 1.000 & 0.691 \\
ESWT-duration & 0.062 & 0.100 & 0.194 & 0.691 & 1.000 \\
CRQ-dyspnoea & 0.111 & -0.079 & 0.015 & 0.325 & 0.226 \\
CRQ-fatigue & 0.243 & 0.361 & 0.552 & 0.302 & 0.161 \\
\hline
\end{tabular}

